\title{
A garantia ao direito à convivência familiar e comunitária em foco
}

\author{
The ensure the right to live in a family and \\ community environment on focus
}

Aline Cardoso SIQUEIRA ${ }^{1}$

\begin{abstract}
Resumo
Este estudo objetivou discutir criticamente a legislação brasileira, em especial o Código de Menores, o Estatuto da Criança e do Adolescente e a Nova Lei da Adoção, no que tange à garantia do direito à convivência familiar e comunitária de crianças e adolescentes institucionalizados. Foi realizada uma análise teórica assistemática da legislação brasileira, com base em pesquisas documentais e bibliográficas. A análise demonstra uma importante evolução tanto no entendimento da infância e juventude quanto nas formas de enfrentamento e atendimento a crianças e adolescentes em situação de vulnerabilidade social. Apesar de o Estatuto da Criança e do Adolescente já representar um avanço em comparação ao Código de Menores, a Nova Lei Nacional da Adoção configura-se um verdadeiro motor para a mudança de paradigma, tendo em vista que apresenta diretrizes específicas para a garantia do direito à convivência familiar e comunitária de crianças e adolescentes institucionalizados.
\end{abstract}

Unitermos: Defesa da criança e do adolescente. Estatuto. Institucionalização. Relações familiares.

\begin{abstract}
The aim of this study was to critically discuss Brazilian law, especially the Children's Code, Children and Adolescent Statute and New National Adoption Law, with regard to guaranteeing the right of institutionalized children and adolescents to live in a family and community environment. Theoretical and unsystematic analysis was performed of the Brazilian legislation based on bibliographical and documentary research. Analysis oflegislation shows an important development both in the understanding of childhood and youth as well as in the ways to handle and assist children and adolescents in a situation of socialvulnerability. Although Children and Adolescent Statute represents an advance compared with the Children'Code, the New National Adoption Law is a real engine for paradigm changes, since it presents specific guidelines to guarantee of the right of institutionalized children and adolescents to live in a family and community environment.
\end{abstract}

Uniterms: Children advocacy. Institutionalization. Family relations. Bylaws, health law.

Atualmente, a garantia do direito à convivência familiar e comunitária está em foco nos centros acadêmicos e nas entidades governamentais e não governamentais de proteção à infância e juventude. Existe um consenso de que são necessárias medidas de pro- moção à permanência da criança e/ou adolescente na família de origem, seja ela nuclear ou extensa. Esse posicionamento influencia o processo de institucionalização de crianças e adolescentes, que tem sofrido modificações, especialmente após o Estatuto da Criança e do

$\cot$

1 Universidade Federal de Santa Maria, Programa de Pós-Graduação em Psicologia. R. Floriano Peixoto, 1750, Sala 319, Centro, 97015-372, Santa Maria, RS, Brasil. E-mail: <alinecsiq@gmail.com>. 
Adolescente (ECA). Assim, o objetivo deste trabalho é discutir criticamente a legislação brasileira, em especial o Código de Menores (Brasil, 1979), o ECA (Brasil, 1990) e a Nova Lei Nacional da Adoção (Brasil, 2009), no que tange à garantia do direito à convivência familiar e comunitária de crianças e adolescentes institucionalizados. Para atingir tal objetivo, foi realizada uma análise teórica assistemática da legislação brasileira, com base em pesquisas documentais e bibliográficas a respeito do tema.

\section{Percurso histórico da legislação: Código de Menores}

A legislação que outorga os direitos das crianças e adolescentes tem mudado gradativamente. Muitos pesquisadores das áreas da Psicologia, Antropologia, Sociologia, Educação e Direito têm se interessado pelo estudo do percurso histórico da legislação voltada à proteção da infância e juventude em risco (Cruz, Hillesheim \& Guareschi, 2005; Fante \& Cassab, 2007; Fonseca, 1987, 1993, 1995; Marcílio, 1997; Priore, 1996; Irene Rizzini \& Irma Rizzini, 2004; Siqueira \& Dell'Aglio, 2006, 2011).

O Código de Menores (Brasil, 1979), elaborado em 1927 (Decreto n 17.943/27) e revisado em 1979 (Lei $\left.n^{\circ} 6.697 / 79\right)$, foi o primeiro documento legal que legislou sobre a infância e adolescência desamparadas. Essa lei considerava a criança e o adolescente como "menores", estabelecendo estratégias de controle e disciplina para os "desviados". Quando havia o afastamento familiar, ocasionado seja por abandono, violência ou mesmo em decorrência de comportamento infrator, as crianças e adolescentes ingressavam em instituições de grande porte, com atendimento coletivizado e sem a perspectiva de retorno à família ou de ressocialização. Instituições com essas características foram nomeadas como instituições totais (Goffman, 1961), sendo que muitos autores destacam os efeitos prejudiciais ocasionados pelo atendimento aí realizado (Cabral, 2002; Guirado, 1986; Marin, 1998, 1999; Saraiva, 2002). Pode-se constatar que no Código de Menores (Brasil, 1979) não estava presente a preocupação com o desenvolvimento das crianças e adolescentes, nem o seu reconhecimento 438 como sujeito de direitos e deveres em situação peculiar.
Um dos objetivos das instituições totais, segundo Goffman (1961), era cuidar de pessoas incapazes e inofensivas, tal como as crianças e adolescentes institucionalizados. Nesses locais, a convivência era permeada muitas vezes pela violência e por regras da instituição, a qual era desvinculada das necessidades dos internos e buscava controlá-los para garantir seu funcionamento (Goffman, 1961). Ainda, as instituições possuíam uma rotina rígida, como horários fixos para acordar, tomar banho, fazer as refeições, brincar e estudar, entre outros. As crianças e os adolescentes compartilhavam peças do vestuário e objetos pessoais, de modo que a mesma roupa era usada ora por uma, ora por outra. Outro aspecto presente era a restrição da liberdade das crianças e adolescentes em medida de proteção, visto que eles permaneciam dentro dos muros da instituição e todos os atendimentos eram geralmente aí prestados, como consultas médicas, psicológicas e odontológicas. Inclusive o acesso à escola era proporcionado nos limites da entidade.

Ainda que instituições de acolhimento devam apresentar outra proposta de atendimento, é possível encontrar, na prática cotidiana, entidades com características de instituições totais (Prada, Williams \& Weber, 2007; Siqueira \& Dell'Aglio, 2011). O acolhimento institucional com tais características de funcionamento pode causar danos ao desenvolvimento de crianças e adolescentes, como problemas de comportamento, psicopatologias e dificuldades de lidar com aspectos da vida diária (Albornoz, 1998; Siqueira \& Dell'Aglio, 2006).

Para combater esse paradigma, o Estatuto da Criança e do Adolescente (Brasil, 1990) propôs uma reformulação no modo de funcionamento das entidades de atendimento às crianças e aos adolescentes em medida protetiva, alterando o cotidiano de muitas instituições (Siqueira \& Dell'Aglio, 2006).

\section{O legado do Estatuto da Criança e do Adolescente}

Em 1990, foi promulgado o ECA (Lei n 8069/90) (Brasil, 1990) e com ele mudanças importantes passaram a ser realizadas nas instituições de acolhimento. O Estatuto da Criança e do Adolescente apresenta uma nova definição de infância e adolescência, conforme a qual as crianças e os adolescentes passam de "objetos de 
tutela", noção presente no Código de Menores (Brasil, 1979), a "sujeitos de direitos e deveres" (Brasil, 1990, Art. $6^{\circ}$ ). Por outro lado, a literatura afirma que o ECA é resultado de um movimento realizado por uma parcela da sociedade civil brasileira participante das discussões advindas da Declaração Universal dos Direitos da Criança, em 1959, e da Convenção sobre Direitos da Criança, em 1989. Assim, a ideia de criança e adolescente como sujeitos em desenvolvimento ainda não estava compartilhada por grande parte da sociedade à época da promulgação do ECA (Santana, 2003).

O acolhimento institucional é uma medida de proteção integral e especial, de caráter provisório e excepcional, através da qual a guarda provisória das crianças e adolescentes é assumida pelo dirigente da instituição de acolhimento (Brasil, 1990; Gulassa, 2006). O Estatuto da Criança e do Adolescente (Brasil, 1990) prevê um conjunto de medidas a serem tomadas em caso de suspeita ou violação dos direitos da criança ou adolescente, sendo a medida de proteção de acolhimento institucional a sétima opção (Brasil, 1990, Art. 101). Antes da retirada da criança ou do adolescente da família, devem-se esgotar as demais medidas. Frente à violação ou suspeita de violação dos direitos da criança e do adolescente, as autoridades competentes podem determinar as seguintes medidas: "I) encaminhamento aos pais ou responsáveis, mediante termo de responsabilidade; II) orientação, apoio e acompanhamento temporários; III) matrícula e frequência obrigatórias em estabelecimento oficial de ensino fundamental; IV) inclusão em programa comunitário ou oficial de auxílio à família, à criança e ao adolescente, V) requisição de tratamento médico, psicológico ou psiquiátrico, em regime hospitalar ou ambulatorial; VI) inclusão em programa oficial ou comunitário de auxílio, orientação e tratamento a alcoólatras e toxicômanos; VII) abrigo em entidade e VIII) colocação em família substituta" (Brasil, 1990, Art. 101).

Para que uma criança ou adolescente seja afastado da família de origem e ingresse em uma instituição de acolhimento, deve ser verificada a presença de fatores de risco em seu contexto de vida, como violência e abandono, bem como devem ser esgotadas outras medidas de proteção prioritárias, como sua colocação na família extensa, por exemplo. Assim, poder-se-á proteger a criança, sem que haja rompimento dos vínculos familiares e institucionalização, de modo a promover o direito à convivência familiar e comunitária.

Considerando o direito à convivência familiar e comunitária, o ECA (Brasil, 1990) determina o fim do isolamento presente na institucionalização em décadas anteriores, a desinstitucionalização no atendimento de crianças e adolescentes em situação de abandono e a valorização do papel da família, das ações locais e das parcerias no desenvolvimento de atividades de promoção desse direito, trazendo mudanças no panorama do funcionamento das instituições de acolhimento (Irene Rizzini \& Irma Rizzini, 2004; Silva, 2004). A partir do fim do isolamento, foi preconizada a extinção dos atendimentos institucionalizados, fazendo com que as crianças e os adolescentes tivessem acesso aos serviços oferecidos em sua comunidade, como atendimento no posto de saúde e ingresso na escola local, entre outras atividades. Tais medidas minimizariam os efeitos da institucionalização, visto que as crianças e os adolescentes acolhidos estão em contato com o mundo para além dos muros da instituição, como demonstrado pelo estudo de Siqueira, Zoltowski, Giordani, Otero e Dell'Aglio (2010). Ao investigar o processo de reinserção familiar de adolescentes institucionalizados por até 10 anos, as pesquisadoras encontraram uma dificuldade importante dos adolescentes em tomarem decisões simples no cotidiano, como fazer compras na mercearia ou pegar um ônibus.

Deve-se considerar também que o direito à convivência familiar e comunitária está diretamente relacionado ao processo de desligamento institucional e de reinserção familiar, visto que a medida protetiva do acolhimento institucional é excepcional e provisória (Brasil, 1990, Art. 101). Assim, torna-se necessário promover o retorno à família de origem da forma mais segura e rápida possível. A partir dessas considerações, o ECA (Brasil, 1990) propõe uma série de medidas para que sejam mantidos os vínculos afetivos das crianças e adolescentes institucionalizados com seus familiares, sendo responsabilidade da equipe das instituições de acolhimento a promoção, a avaliação e a preparação dos processos de reinserção familiar.

Contudo, muitas crianças e adolescentes ainda permanecem institucionalizados durante anos, sem que Ihes seja garantido o direito à convivência familiar e comunitária (Fante \& Cassab, 2007; Silva, 2004). Muitos 
estudos têm demonstrado que o tempo de institucionalização tem efeito negativo ao longo do tempo, sendo que aquelas crianças e adolescentes com mais tempo de institucionalização podem apresentar menor desempenho escolar e pior percepção de apoio em sua rede social e afetiva (Dell'Aglio \& Hutz, 2004; Siqueira, 2009). Para Juliano (2005), as dificuldades na efetivação do caráter provisório da medida de acolhimento institucional são: 1) a falta de integração das políticas sociais existentes; 2) a dificuldade de interação e comunicação entre as entidades que trabalham com crianças e adolescentes em situação de risco pessoal e social; 3) a ausência de objetivos comuns entre as entidades; 4) a existência de ações pontuais e fragmentadas; 5) a fragilidade dos recursos humanos nos acolhimentos, tanto em quantidade como em qualificação; e ainda 6) a fragilidade das famílias, que se posicionam passivamente frente às ações que poderiam resultar no desligamento institucional de seus filhos.

Além disso, a determinação do ECA de que as equipes técnicas das instituições de acolhimento são as responsáveis pelo desligamento institucional e reinserção familiar não garantiu a criação dessas equipes nesse momento. De fato, durante vários anos da existência do ECA, muitas instituições ainda não haviam montado suas equipes técnicas, com psicólogos, assistentes sociais, educadores com formação em infância e juventude, entre outros profissionais. Uma das hipóteses para a não contratação de equipes técnicas pode ser a carência de recurso financeiro desses acolhimentos. Segundo Irene Rizzini, Irma Rizzini, Naiffe Baptista (2006), a maioria das instituições de acolhimento é filantrópica e sustentada por recursos da sociedade civil, entidades internacionais e parcas verbas advindas das agências governamentais de assistência social. Pode-se perceber que esta problemática não tem sido prioridade pelos governos ao longo dos anos. A inexistência de equipes técnicas nas instituições reflete-se não só na falta de garantia do direito à convivência familiar e comunitária, mas também na má condução dos processos de desligamento e na disponibilidade de atendimento de caráter assistencialista, predominante nesse campo em décadas anteriores.

Outra importante determinação do ECA (Brasil, 1990) foi o reordenamento institucional. Segundo essa 440 legislação, as instituições de acolhimento devem as- sumir um caráter residencial, oferecendo atendimento personalizado, em pequenas unidades e a grupos reduzidos (Arts. 92, 93 e 94). Além disso, não deve restringir nenhum direito que não tenha sido objeto de restrição por parte do Sistema Judiciário; deve também preservar a identidade da criança e adolescente, oferecer ambiente de respeito e dignidade, propiciar escolarização, profissionalização e atividades culturais, esportivas e de lazer, entre outras (Art. 94). Comparado o formato de acolhimento idealizado pelo ECA ao funcionamento das instituições totais, observa-se a existência de um grande abismo entre tais paradigmas, exigindo uma profunda reformulação tanto do espaço físico das instituições quanto da forma de funcionamento em si. Entretanto, o principal desafio estabelecido pelo ECA não foi o da redução das instalações físicas dos acolhimentos institucionais, mas sim o da construção e implementação de um programa socioeducativo (Art. 90). Esse programa deveria buscar o desenvolvimento pleno das crianças e adolescentes em acolhimento institucional, vendo-os como seres humanos em situação peculiar de desenvolvimento, com potencialidades e limitações, dissociando o acolhimento da função exclusivamente assistencialista e da ideia de depósito de crianças e adolescentes "problemáticos", vítimas de violência e rejeitados pela família (Guará, 2006).

Precedendo a Nova Lei Nacional da Adoção (Brasil, 2009), em 2004 e 2005, o Plano Nacional de Promoção, Defesa e Garantia dos Direitos de Crianças e Adolescentes à Convivência Familiar e Comunitária foi construído por entidades que atuam no campo da assistência social, com o objetivo de fortalecer as famílias que tinham filhos em situação de institucionalização e potencializar as ações de reinserção familiar (Rizzini et al., 2006; Siqueira et al., 2010). Assim, em 2009, foi sancionada a Lei 12.010/2009 (Brasil, 2009), nomeada como Nova Lei Nacional da Adoção, propondo diretrizes mais específicas quanto à permanência da criança e do adolescente em instituições de acolhimento, reiterando o direito à convivência familiar e comunitária, tema a ser tratado na próxima seção.

\section{Inovações da Nova Lei Nacional da Adoção}

Apesar de recente, a Lei 12.010/2009 (Brasil, 2009) já tem movimentado o campo da assistência social no Brasil. A lei modifica o texto do próprio Estatuto da 
Criança e do Adolescente (Brasil, 1990). Assim, o Art. 101, por exemplo, tem o inciso VII alterado de "abrigo em entidade" para "acolhimento institucional"; ganha o inciso VIII (inclusão em programa de acolhimento familiar); e renumera como IX o anterior inciso VIII (colocação em família substituta).

Ainda, a partir da Lei 12.010/2009 (Brasil, 2009) as entidades que atendem a crianças e adolescentes em situação de suspeita ou violação dos direitos passaram a ser nomeadas como "acolhimentos institucionais", e não mais abrigos. Ferreira, Dói e Baldacim (2009) apresentam as mudanças propostas pela nova lei a partir de uma tabela comparativa entre ela e o ECA (Brasil, 1990), indicando de maneira sistemática as inovações.

A Nova Lei Nacional da Adoção (Brasil, 2009) traz a prerrogativa de que o afastamento familiar e a institucionalização não devem ser a primeira opção frente à constatação da ameaça ou violação dos direitos da criança e do adolescente, reiterando outras opções a serem consideradas antes do acolhimento, já descritas pelo ECA (Brasil, 1990). Uma alternativa seria a busca da resolução da problemática junto à família com a ajuda da rede de atendimento. Por exemplo, em uma família cujas crianças sejam vítimas de violência doméstica por parte da mãe e do companheiro, que esteja desempregado e faça uso de álcool e drogas ilícitas, a partir da avaliação da situação, o Conselho Tutelar poderia: 1) indicar tratamento para os cuidadores; 2) acompanhar e orientar a mãe para que ela utilize práticas educativas indutivas, ao invés de coercitivas e punitivas; 3) afastar o agressor da família, caso haja a negação do tratamento ou a perpetuação da violência e do uso de drogas; 4) inserir os cuidadores em programas de capacitação ao trabalho e/ou em programas de transferência de renda mínima, como o bolsa-família e 5) colocar as crianças na família extensa, como casa dos avós, tios ou padrinhos. Tais estratégias buscam evitar a institucionalização das crianças. Contudo, caso a situação não seja modificada e a institucionalização seja a única opção, as crianças poderão ser inseridas em um acolhimento institucional, devendo ser iniciado um trabalho junto à família para que a medida de proteção seja provisória, como preconiza a legislação (Brasil, 1990; 2009).

A família extensa ganha destaque e responsabilidade na Nova Lei Nacional da Adoção (Brasil, 2009, Art. 101). A legislação traz a prerrogativa da parceria e da cooperação dos membros da família extensa, evitando a institucionalização. Nessa questão, está imbuída a ideia de que o afastamento familiar não é o melhor caminho, visto que a ele estão atrelados sentimentos de culpa, rejeição e sofrimento, além da ruptura do vínculo afetivo com familiares e amigos e do afastamento da comunidade e escola, aspectos que podem gerar efeitos negativos ao desenvolvimento das crianças e adolescentes. Muitos pesquisadores já haviam mencionado a importância da família extensa para as famílias em situação de vulnerabilidade; aquela assume um papel essencial de apoio emocional e instrumental para o membro em dificuldade (Fonseca, 1987; Siqueira \& Dell'Aglio, 2006).

Uma implicação decorrente dessa nova forma de manejar as situações de ameaça ou violação dos direitos da criança e do adolescente corresponde à formação e à capacitação dos agentes sociais para avaliar, analisar e determinar as melhores alternativas à institucionalização. O Estatuto da Criança e do Adolescente (Brasil, 1990) atribui ao Conselho Tutelar o papel de zelar pelo cumprimento dos direitos da criança e do adolescente, sendo ele o responsável pela aplicação das medidas previstas no Art. 129 (Brasil, 1990). Entre elas, estão: encaminhar os cuidadores para serviços e programas de proteção à família; encaminhar a serviços de orientação e tratamento a usuário de álcool e outras drogas; encaminhar a tratamento psicológico ou psiquiátrico; atender às crianças, adolescentes e suas famílias (Brasil, 1990, Arts. 129 e 136).

A questão que surge é se esses profissionais possuem a capacitação e o treinamento necessários para desenvolver tais atribuições de forma adequada. Segundo o ECA (Brasil, 1990, Art. 133), os requisitos para o candidato a conselheiro tutelar são: possuir reconhecida idoneidade moral, idade superior a 21 anos e residir no município. Assim, pode-se perceber que não há exigências quanto à formação específica para desempenhar a função de conselheiro tutelar. De fato, muitos conselheiros tutelares não possuem formação na área de desenvolvimento humano, violência doméstica e direitos da criança e do adolescente, como também não contam com o suporte de profissionais capacitados para a tomada de decisões e para os encaminhamentos, dificultando o pleno desenvolvimento de suas funções (Costa et al., 2007; Frizzo \& Sarriera, 2006; Milane \& Loreiro, 
2008; Souza, Teixeira \& Silva, 2003). Milani e Loureiro (2008) alertam que, como o Conselho Tutelar é um espaço de escuta e conscientização dos direitos do cidadão, é urgente a necessidade de uma formação para a função de conselheiros tutelares, visto que esses agentes sociais devem estar preparados para se sensibilizar com as necessidades do núcleo familiar, de modo a lidar com elas de forma abrangente, adequada e ética.

As equipes técnicas dos acolhimentos ganharam inúmeras atribuições específicas na Nova Lei Nacional da Adoção (Brasil, 2009), como a elaboração obrigatória de um plano individual de reintegração familiar para cada criança e adolescente que ingressar no acolhimento (Art. 101, $\$ 4^{\circ}$ e $5^{\circ}$ ); mediação entre a criança e o adolescente e a autoridade judiciária (Art. 101, § $8^{\circ}$ ); emissão de relatório sobre a situação da criança ou adolescentes à autoridade judiciária a cada seis meses (Art. 19, § $1^{\circ}$ ); recomendação ou não do desligamento institucional e do retorno à família (Art. 101, § $8^{\circ}$ ), entre outras funções. Essas determinações não existiam no Estatuto da Criança e do Adolescente (Brasil, 1990).

A nova lei atribui à equipe das instituições de acolhimento o papel de realizar o processo de reinserção familiar das crianças e adolescentes institucionalizados. Como o trabalho dessa equipe passou a ser indispensável nos acolhimentos, muitas instituições estão contratando psicólogos e assistentes sociais. Com a obrigatoriedade da equipe técnica, os acolhimentos têm buscado parcerias com a iniciativa pública e privada para a contratação. Acredita-se que essa inovação fará grande diferença na garantia do direito à convivência familiar e comunitária, visto que profissionais da Psicologia e Serviço Social, capacitados na área de família, infância e adolescência em situação de vulnerabilidade, têm o embasamento teórico-prático para a tomada de decisão nesses processos.

Para que tanto o Conselho Tutelar quanto as equipes técnicas das instituições de acolhimento possam realizar seu trabalho (preservação ou reinserção familiar), torna-se imprescindível a existência de uma rede de atendimento em sintonia com as necessidades das famílias. Dessa forma, por mais que a legislação preconize o atendimento de crianças, adolescentes e suas famílias por programas sociais, educacionais, instituições de assistência à saúde física e mental e de reabilitação, de nada valerá essa determinação se a rede de atendimento não disponibilizar tais atendimentos ou não estiver apta para atender à demanda. Pesquisadores têm apontado a escassez de programas de fortalecimento e reabilitação familiar, bem como a limitação do atendimento a poucos casos (Rizzini et al., 2006). Além disso, Siqueira e Dell'Aglio (2011) destacam que o programa-padrão do governo - transferência de renda mínima - não tem sanado muitos dos problemas familiares.

Outra inovação da Nova Lei Nacional da Adoção (Brasil, 2009) foi a limitação para dois anos do tempo de permanência da criança e/ou adolescente em instituição de acolhimento (Brasil, 2009, Art. 19, § 2º). Além disso, deverão ser realizadas avaliações periódicas dos casos, sempre buscando a garantia ao direito à convivência familiar e comunitária, com o retorno da criança à família nuclear ou extensa, ou sua colocação em família adotiva ou substituta. Com essa determinação, a legislação busca evitar os longos períodos de institucionalização de décadas anteriores e possibilitar a convivência familiar por meio do aumento das possibilidades de adoção.

Por outro lado, sabe-se que o perfil escolhido pelos candidatos a adotantes, no momento do cadastramento, é ser recém-nascido, saudável, de pele clara e olhos azuis, o que não condiz com a realidade das crianças que estão em condições de adoção no Brasil (Noal \& Neiva-Silva, 2007; Ziegler \& Siqueira, 2010). Mesmo que o limite de dois anos de institucionalização tenha sido preconizado para garantir o direito à convivência familiar e comunitária, essa determinação pode não resultar em aumento nos processos de adoção, visto que o perfil desejado pelos pais adotantes é diferente do perfil das crianças em acolhimento institucional. Durante os dois anos, a família deverá receber ajuda, incentivo e investimento para solucionar os problemas e riscos que levaram ao afastamento do filho, e, a menos que os pais autorizem legalmente a adoção, a criança irá permanecer nesse período no acolhimento, diminuindo a cada dia as suas chances de ser adotada.

Por fim, faz-se importante destacar um risco presente na busca pela garantia à convivência familiar e comunitária. Fonseca (2005) demonstra que, ao efetivar a provisoriedade da medida de acolhimento, muitas instituições podem promover a reinserção de crianças e adolescentes em suas famílias, sem que estas tenham condições de reassumir a parentalidade. A política da 
brevidade institucional, na qual há uma busca pelo desligamento a qualquer custo, representa o outro extremo da garantia da provisoriedade da medida de proteção e da busca pela efetivação do direito à convivência familiar, sendo, segundo Fonseca (2005), inspirada no desejo de corrigir os erros das políticas do passado.

\section{Considerações Finais}

Este artigo procurou discutir criticamente a legislação brasileira direcionada à infância e juventude, no que tange à garantia do direito à convivência familiar e comunitária de crianças e adolescentes institucionalizados. A partir da apresentação e discussão do Código de Menores (Brasil, 1979), do ECA (Brasil, 1990) e da Nova Lei Nacional da Adoção (Brasil, 2009), foi possível constatar uma evolução tanto no entendimento da questão da infância e juventude, quanto nas formas de enfrentamento e atendimento das crianças e adolescentes em situação de risco e vulnerabilidade social. O ECA (Brasil, 1990) representa uma dicotomia com a legislação passada, propondo grandes alterações no campo da assistência social às crianças e adolescentes em situação de institucionalização, e a Lei Nacional da Adoção (Brasil, 2009) vem reiterar e sistematizar tais alterações. Por exemplo, delimitou o tempo de institucionalização, determinou análise periódica dos casos e emissão de relatórios à autoridade jurídica, solicitou a presença da equipe técnica nas instituições ao exigir que os relatórios sejam emitidos por psicólogos e assistentes sociais, passou a chamar as entidades de acolhimento, entre outros aspectos marcantes. Houve mudanças significativas da legislação, as quais têm refletido em alterações qualitativas e efetivas na prática da assistência social no Brasil, em especial quanto à garantia do direito à convivência familiar e comunitária. Por mais que se saiba que mudanças na legislação não necessariamente correspondem a mudanças na prática cotidiana, pode-se perceber que movimentos no interior das instituições de acolhimento têm ocorrido de forma mais acelerada a partir da Lei no 12.010 (Brasil, 2009).

Para que as determinações do ECA (Brasil, 1990) e da Nova Lei Nacional da Adoção (Brasil, 2009) sejam de fato incorporadas ao cotidiano da assistência social, fazem-se necessárias várias ações: 1) capacitar os Conselhos Tutelares para que tais agentes sociais possam executar suas atribuições de forma competente e adequada; 2) fortalecer as famílias das crianças e adolescentes; 3) valorizar e fortalecer a família extensa; 4) ampliar os programas sociais e atendimentos socioeducativos; 5) ampliar os programas de assistência à saúde física e mental de modo a atender à demanda e 6) criar, nas instituições de acolhimento, equipes técnicas capacitadas na área da infância e juventude em situação de risco e vulnerabilidade social. Somente com uma rede de atendimento competente, capacitada, suficiente e articulada, é que se poderá dar encaminhamentos efetivos aos casos e fazer valer o direito à convivência familiar e comunitária.

Resta, por fim, destacar a necessidade de se realizarem pesquisas futuras que avaliem o impacto da Nova Lei Nacional da Adoção para as instituições de acolhimento e para os processos de reinserção familiar. Tendo em vista a grande dimensão do Brasil, é possível que o movimento ocasionado por essa lei não seja igual em todo o território nacional, considerando-se as especificidades das regiões e municípios do País.

\section{Referências}

Albornoz, A. C. G. (1998). Os efeitos preventivos e curativos dos cuidados parentais substitutos com relação à doença mental graves: fundamentando a práxis. Alethéia, 7, 27-33.

Brasil. (1979, 11 de outubro). Lei no 6697, de 10 de outubro de 1979. Código de Menores. Diário Oficial da União, Seção 1, n. 196.

Brasil. (1990, 16 de julho). Lei no 8.069, de 13 de julho de 1990. Estatuto da Criança e do Adolescente. Diário Oficial da União, p.13.563.

Brasil. Casa Civil. (2009). Lei no 12.010, de 3 de agosto. Diário Oficial da União, p. 1. Recuperado em março 9, 2010, disponível em <http://www.planalto.gov.br/ccivil_03/_Ato 2007-2010/2009/Lei/L12010.htm>.

Cabral, C. (2002). Mudança de paradigma: um desafio. In Terra dos Homens (Ed.), Cuidar de quem cuida: reintegração familiar de crianças e adolescentes em situação de rua (pp.1316). Rio de Janeiro: Booklink Publicações.

Convenção dos Direitos da Criança. (1989). Assembléia Nacional das Nações Unidas. Recuperado em maio 11, 2010, disponível em <http://www.unicef.org/brazil/pt/ resources_10120.htm>.

Costa, M. C., Carvalho, R. C., Bárbara, J. F., Santos, C. A., Gomes, W. A., \& Sousa, H. L. (2007). O perfil da violência contra crianças e adolescentes, segundo registros de Conselhos Tutelares: vítimas, agressores e manifestações de violência. Ciência e Saúde Coletiva, 12 (5), 1129-1141.

Cruz, L., Hillesheim, B., \& Guareschi, N. (2005). Infância e políticas públicas: um olhar sobre as práticas psi. Psicologia \& Sociedade, 17 (3), 42-49. 
Declaração Universal dos Direitos da Criança. (1959). Assembléia Nacional das Nações Unidas. Recuperado em maio 11, 2010, disponível em <http://www.canadiancrc. com/ UN_Declaration_on_the_Rights_of_the_Child. aspx>.

Dell'Aglio, D., \& Hutz, C. (2004). Depressão e desempenho escolar em crianças e adolescentes institucionalizados. Psicologia: Reflexão e Crítica, 17 (3), 341-350.

Fante, A. P., \& Cassab, L. A. (2007). Convivência familiar: um direito à criança e ao adolescente institucionalizado. Revista Textos \& Contextos, 6 (1), 154-174.

Ferreira, L. A. M., Dói, C. K. T., \& Baldacim, E. (2009). Quadro comparativo ECA e a Lei No 12.010/09. Recuperado em dezembro 14, 2010, disponível em <http://www.pjpp. sp.gov.br/2004/artigos/42.pdf>.

Fonseca, C. (1987). O internato do pobre: Febem e a organização doméstica em um grupo porto-alegrense de baixa renda. Temas IMESC, Sociedade, Direito, Saúde, 4 (1), 21-39.

Fonseca, C. (1993). Criança, família e desigualdade social no Brasil. In I. Rizzini (Org.), A criança no Brasil hoje: desafio para o terceiro milênio (pp.113-131). Rio de Janeiro: Editora Universitária Santa Úrsula.

Fonseca, C. (1995). Caminhos da adoção. São Paulo: Cortez.

Fonseca, C. (2005). Conexões internacionais em famílias acolhedoras. Praia Vermelha: Estudos de Política e Teoria Social, 13, 154-173.

Frizzo, K. R., \& Sarriera, J. C. (2006). Práticas sociais com crianças e adolescentes: o impacto dos conselhos tutelares. Psicologia: Ciência e Profissão, 26 (2), 198-209.

Goffman, E. (1961). Manicômios, prisões econventos. São Paulo: Perspectiva.

Guará, I. M. F. (2006). Abrigo: comunidade de acolhida e socioeducação. In M. V. Baptista (Org.), Abrigo: comunidade de acolhida e socioeducação (pp.63-75). São Paulo: Instituto Camargo Corrêa.

Guirado, M. (1986). Instituição e relações afetivas: o vínculo com o abandono. São Paulo: Summus.

Gulassa, M. L. C. (2006). A fala dos abrigos. In M. V. Baptista (Org.), Abrigo: comunidade de acolhida e socioeducação (pp.53-61). São Paulo: Instituto Camargo Corrêa.

Juliano, M. C. (2005). A influência da ecologia dos ambientes de atendimento no desenvolvimento de crianças e adolescentes abrigados. Dissertação de mestrado não-publicada, Programa de Pós-Graduação em Educação Ambiental, Fundação Universidade Federal do Rio Grande, Natal.

Marcílio, M. L. (1997). A roda dos expostos e a criança abandonada na história do Brasil: 1726-1950. In M. Freitas (Org.), História social da infância no Brasil (pp.51-76). São Paulo: Cortez.

Marin, I. S. K. (1998). Instituições e violência: violência nas instituições. In D. Levisky (Org.), Adolescência pelos caminhos da violência (pp.101-112). São Paulo: Casa do Psicólogo.

Marin, I. S. K. (1999). Febem, família e identidade: o lugar do outro. São Paulo: Editora Escuta.

Milani, R. G., \& Loureiro, S. R. (2008). Famílias e violência doméstica: condições psicossociais pós ações do Conselho Tutelar. Psicologia: Ciência e Profissão, 28 (1), 50-67.
Noal, J., \& Neiva-Silva, L. (2007). Adoção, adoção tardia e apadrinhamento afetivo: intervenções em relação a crianças e adolescentes. In C. S. Hutz (Org.), Prevenção e intervenção em situações de risco e vulnerabilidade (pp.7-48). São Paulo: Casa do Psicólogo.

Prada, C., Williams, L., \& Weber, L. (2007). Abrigos para crianças vítimas de violência doméstica: funcionamento relatado pelas crianças e pelos dirigentes. Psicologia: Teoria e Prática, 9 (2), 14-25.

Priore, M. D. (1996). O papel branco, a infância e os jesuítas na Colônia. In M. Priore (Org.), História da criança no Brasil (pp.10-27). São Paulo: Contexto Editora.

Rizzini, I., \& Rizzini, I. (2004). A institucionalização de crianças no Brasil. Rio de Janeiro: PUC-Rio.

Rizzini, I., Rizzini, I., Naiff, L., \& Baptista, R. (2006). Acolhendo crianças e adolescentes: experiências de promoção do direito à convivência familiar e comunitária no Brasil. São Paulo: Cortez.

Santana, J. P. (2003). Instituições de atendimento a crianças e adolescentes em situação de rua: objetivos atribuídos por seus dirigentes e pelos jovens atendidos. Dissertação de mestrado não-publicada, Programa de Pós-Graduação em Psicologia do Desenvolvimento, Universidade Federal do Rio Grande do Sul, Porto Alegre.

Saraiva, J. E. M. (2002). Contextualizando a problemática. In Associação Brasileira Terra dos Homens (Org.), Cuidar de quem cuida: reintegração familiar de crianças e adolescentes em situação de rua (pp.7-12). Rio de Janeiro: Booklink Publicações.

Silva, E. R. (2004). O direito à convivência familiare comunitária: os abrigos para crianças e adolescentes no Brasil. Brasília: IPEA.

Siqueira, A. C. (2009). Crianças, adolescentes etransições ecológicas: instituições de abrigo e família como contextos de desenvolvimento. Tese de doutorado não-publicada, Programa de Pós-Graduação em Psicologia, Universidade Federal do Rio Grande do Sul, Porto Alegre.

Siqueira, A. C., \& Dell'Aglio, D. D. (2006). O impacto da institucionalização na infância e na adolescência: uma revisão de literatura. Psicologia \& Sociedade, 18 (1), 71-80.

Siqueira, A. C., \& Dell'Aglio, D. D. (2011). Políticas públicas de garantia do direito à convivência familiar e comunitária. Psicologia \& Sociedade, 23 (2), 262-271.

Siqueira, A. C., Zoltowski, A. P., Giordani, J., Otero, T., \& Dell'Aglio, D. D. (2010). Processo de reinserção familiar: estudo de casos de adolescentes que viveram em instituição de abrigo. Estudos de Psicologia (Natal), 15 (1), 7-15.

Souza, M. P. R., Teixeira, D. C. S., \& Silva, M. C. Y. G. (2003). Conselho Tutelar: um novo instrumento social contra o fracasso escolar? Psicologia em Estudo (Maringá), 8 (2), 71-82.

Ziegler, M. H., \& Siqueira, A. C. (2010). Pais por adoção: a adoção na perspectiva dos casais na fila de espera. Psicologia: Teoria e Prática, 12 (2), 200-216.

Recebido em: 4/8/2010

Versão final reapresentada em: 21/12/2011

Aprovado em: 27/1/2012 